() Н.Н. Мусина ${ }^{1 *}$, Т.В. Саприна', Т.С. Прохоренко ${ }^{1,2}$, А.П. Зима'

${ }^{1}$ Сибирский государственный медицинский университет, Томск, Россия

${ }^{2}$ Томский региональный центр крови, Томск, Россия

Обоснование. Актуальным представляется вопрос состояния воспалительного статуса и обмена железа у лиц с нарушениями углеводного обмена (НУО), однако довольно мало работ посвящено исследованию взаимосвязей между метаболическими параметрами, в том числе параметрами обмена липидов, показателями воспаления и состоянием феррокинетики при сахарном диабете 1 и 2 типов в сравнительном аспекте.

Цель. Установить направленность изменений воспалительного статуса и состояния феррокинетики у пациентов с сахарным диабетом 1 и 2 типа в зависимости от нарушений липидного обмена.

Методы. В исследование включено 48 пациентов с сахарным диабетом 1 типа, 81 пациент с сахарным диабетом 2 типа; 11 человек с ожирением без НУО составили группу сравнения, 17 здоровых добровольцев - группу контроля. Субклиническое воспаление оценивали по уровням высокочувствительного С-реактивного белка (СРБ), фактора некроза опухолей-а (ФНО-а) и скорости оседания эритроцитов (СОЭ). Состояние обмена железа оценивали по основным гематологическим показателям (гемоглобин, количество эритроцитов, гематокрит), концентрациям железа сыворотки, трансферрина, ферритина и гепсидина крови. Всем пациентам проводилась оценка липидного обмена, гликированного гемоглобина и микроальбуминурии.

Результаты. У пациентов с сахарным диабетом 1 и 2 типа имело место повышение содержания в крови воспалительных маркеров - ФНО-а, СОЭ и СРБ - относительно пациентов с ожирением и лиц группы контроля. Наибольшая концентрация ФНО-а отмечалась у пациентов с сахарным диабетом 1 типа (15,28 [12,41-24,41] пг/мл), а СРБ (7,00 [3,00-11,85] нг/мл) и СОЭ (18,00 [9,00-27,00] мм/час) - у пациентов с сахарным диабетом 2 типа. В структуре обследованных лиц с сахарным диабетом (вне зависимости от его типа) дислипидемия ІІb в сравнении с менее атерогенной ІІа дислипидемией характеризовалась более высокими значениями СРБ (6,9 [3,00-12,35] и 3,00 [1,80-8,70] нг/мл соответственно), СОЭ (20,00 [10,00-30,00] и 15,00 [5,00-24,50] мм/час соответственно) и ферритина $(114,80$ [48,90-196,45] и 50,90 [19,58-114,10] нг/мл соответственно). Анемия хронических заболеваний при сахарном диабете в сравнении с сидеропенической анемией чаще сопровождалась дислипидемией IIb $\left(\mathrm{X}^{2}=2,743 ; \mathrm{p}=0,098\right)$ и характеризовалась более высоким содержанием атерогенных фракций холестерина.

Заключение. Для лиц с сахарным диабетом 2 типа и более атерогенным профилем дислипидемии (Ilb тип) характерен фенотип локальной воспалительной мезенхимальной реакции печени с повышением сывороточной концентрации острофазных белков, имеющих преимущественно печеночное происхождение (СРБ, ферритин), а для лиц, страдающих сахарным диабетом 1 типа и имеющих менее атерогенный липидный профиль (ІІа тип) - фенотип аутоиммунного, генетически детерминированного воспалительного ответа. Развивающаяся на фоне сахарного диабета анемия хронических заболеваний ассоциирована с более атерогенным липидным профилем, в сравнении с сидеропенической анемией.

КЛЮЧЕВЫЕ СЛОВА: сахарный диабет; дислипидемия; анемия; воспаление; С-реактивный белок; фактор некроза опухолей-а.

\title{
IRON METABOLISM PARAMETERS AND INFLAMMATORY STATUS IN PATIENTS WITH DIABETES MELLITUS AND DYSLIPIDEMIA
}

(c) Nadezhda N. Musina ${ }^{*}$, Tatiana V. Saprina', Tatiana S. Prokhorenko ${ }^{1,2}$, Anastasia P. Zima1

'Siberian State Medical University, Tomsk, Russia

${ }^{2}$ Tomsk Regional Blood Center, Tomsk, Russia

BACKGROUND: Investigating the inflammatory status and iron metabolism in patients with impaired carbohydrate metabolism seems quite relevant, while only few studies are devoted to the relationship between metabolic parameters, including lipid profile, inflammatory status indicators and the state of ferrokinetics in diabetes mellitus types 1 and 2 in a comparative aspect.

AIMS: To establish the direction of changes in the inflammatory status and the state of ferrokinetics in patients with type 1 and type 2 diabetes mellitus depending on lipid metabolism disorders.

MATERIALS AND METHODS: The study included 48 patients with type 1 diabetes, 81 patients with type 2 diabetes; 11 people with obesity without impaired carbohydrate metabolism made up the comparison group, 17 healthy volunteers - the control group. Low-grade inflammation was assessed by the levels of high-sensitive C-reactive protein (CRP), tumor necrosis 
factor- $a$ (TNF- $\alpha$ ), ferritin, and erythrocyte sedimentation rate (ESR). The state of iron metabolism was evaluated by the main hematological parameters (hemoglobin, red blood cell count, hematocrit), serum iron concentrations, transferrin, ferritin and hepcidin concentrations. In all patients lipid metabolism parameters, glycated hemoglobin, and microalbuminuria were measured.

RESULTS: Patients with type 1 and type 2 diabetes mellitus had significantly higher inflammatory markers concentrationsTNF- $a$, ESR, and CRP - in relation to obese patients without impaired carbohydrate metabolism and those in the control group. The highest production of TNF-a was observed in patients with type 1 diabetes mellitus (15.28 [12.41-24.41] pg/ml), whereas CRP $(7.00$ [3.00-11.85] ng/ml) and ESR $(18.00$ [9.00-27.00] $\mathrm{mm} / \mathrm{h})$ were higher in patients with type 2 diabetes. In the structure of the examined individuals with diabetes mellitus (regardless of its type), dyslipidemia type Ilb in comparison with less atherogenic type lla dyslipidemia was characterized by a higher production of CRP (6.9 [3.00-12.35] and 3.00 [1.80-8.70] ng/ml, respectively), ESR (20.00 [10.00-30.00] and $15.00[5.00-24.50] \mathrm{mm} / \mathrm{h}$, respectively) and ferritin (114.80 [48.90-196.45] and 50.90 [19.58-114.10] ng/ml, respectively). Compared to iron deficiency anemia, anemia of chronic diseases in diabetes mellitus patients was more often accompanied by dyslipidemia llb $\left(X^{2}=2.743 ; p=0.098\right)$ and was characterized by a higher content of atherogenic fractions of cholesterol.

CONCLUSIONS: Patients with type 2 diabetes mellitus and a more atherogenic dyslipidemia profile (type llb) have a phenotype of the local inflammatory mesenchymal reaction of the liver with an increase in acute-phase proteins predominantly of hepatic origin (CRP, ferritin), whereas individuals suffering from type 1 diabetes and less atherogenic lipid profile (type lla) have a phenotype of an autoimmune, genetically determined inflammatory response. It has been established that anemia of chronic diseases developing in the background of diabetes mellitus is associated with a more atherogenic lipid profile, compared with iron deficiency anemia.

KEYWORDS: diabetes mellitus; dyslipidemia; anemia; inflammation; c-reactive protein; tumor necrosis factor-a.

\section{ОБОСНОВАНИЕ}

Известно, что сахарный диабет ассоциирован с провоспалительным иммунным статусом и сопровождается повышением уровня циркулирующих маркеров воспаления, при этом в основе сахарного диабета 1 типа лежит органо-специфическое воспаление аутоиммунного характера, которое приводит к гибели $\beta$-клеток островков Лангерганса поджелудочной железы [1-3], при сахарном диабете 2 типа патогенез хронического субклинического воспаления, как правило, рассматривается с точки зрения воспалительной активности, индуцируемой жировой тканью [4-7]. В то же время, имеются данные о том, что уровень цитокинов при сахарном диабете остается высоким даже после коррекции ожирения [8]. Это указывает на важную, однако не единственную роль избыточной жировой ткани в воспалении при сахарном диабете 2 типа: так, гипергликемия сама по себе способна индуцировать экспрессию провоспалительных молекул $\beta$-клетками и приводить к активации факторов роста фибробластов и маркеров воспаления [9, 10]. Достаточно данных, подтверждающих вклад системного воспаления низкой интенсивности в развитие и прогрессирование атеросклеротического процесса, в том числе у лиц с нарушением углеводного обмена [11-13], в связи с чем инсулинорезистентность, гипергликемия, атеросклероз и хроническое воспаление могут рассматриваться как звенья одного патогенетического процесса. Стоит отметить, что как в отечественной, так и в зарубежной литературе представлены преимущественно результаты исследований состояния липидного обмена и воспалительного статуса, а также их взаимного влияния, проводившиеся на отдельных когортах пациентов с сахарным диабетом 1 типа и с сахарным диабетом 2 типа, что не позволяло в сравнительном аспекте оценить вклад свойственных сахарному диабету метаболических расстройств в развитие как системного воспаления, так и нарушений обмена липидов и феррокинетики. Показана роль хронического низкоинтенсивного воспаления в развитии анемического синдрома: цитокины смещают гематопоэз в сторону образования миелоидных клеток, а не эритропоэза, фактор некроза опухолей а (ФНО-а) ингибирует пролиферацию эритроидного предшественника, а также активирует макрофаги для эритрофагоцитоза, что приводит к сокращению жизни эритроцитов, интерлейкин 6 (IL-6) через гепсидин ингибирует высвобождение вторичного железа из макрофагов, вызывая гипоферремию [14]. В настоящее время достаточно актуальным представляется вопрос состояния обмена железа у лиц с нарушениями углеводного обмена [15-17], при этом довольно мало работ посвящено исследованию взаимосвязей между метаболическими параметрами, в том числе параметрами обмена липидов, показателями воспалительного статуса и состоянием феррокинетики при сахарном диабете 1 и 2 типов в сравнительном аспекте.

\section{ЦЕЛЬ}

Установить направленность изменений воспалительного статуса и состояния феррокинетики у пациентов с сахарным диабетом 1 и 2 типов в зависимости от типа нарушений липидного обмена.

\section{МЕТОДЫ}

Дизайн исследования

Обсервационное одноцентровое одномоментное выборочное контролируемое нерандомизированное исследование.

\section{Критерии соответствия}

Критерии включения в основную групnу: наличие установленного диагноза сахарный диабет 1 или 2 типа соответственно, возраст пациента от 18 до 70 лет, стаж заболевания от 1 года до 30 лет, уровень гликированного гемоглобина от 6,5\% до 10,5\%. 
Критерии включения в дополнительную группу: возраст пациента от 18 до 70 лет, отсутствие нарушений углеводного обмена (НУО) по данным исследования гликированного гемоглобина и проведения стандартного теста толерантности к глюкозе с 75 г глюкозы (СТТГ с 75 г глюкозы). Дополнительная группа была разделена на группу сравнения и контроля зависимости от индекса массы тела (ИМТ): в группу сравнения вошли пациенты с ИМТ 30 кг/м кв. и более, в группу контроля - лица с ИМТ от 18,5 до 29,9 кг/м кв.

Критерии невключения: инфекционные заболевания в стадии обострения, специфические инфекционные заболевания, такие как: ВИЧ/СПИД, вирусные гепатиты с любой степенью активности, цирроз печени вирусной и аутоиммунной этиологии, туберкулез; онкологические заболевания; хроническая обструктивная болезнь легких и бронхиальная астма; курение на момент включения в исследование; гемотрансфузии в период 1 месяца до включения в исследование и в настоящий момент; прием препаратов железа; пред- и постоперационный период; острая почечная, печеночная, сердечная недостаточность, скорость клубочковой фильтрации ниже 15 мл/мин, стадия протеинурии; декомпенсация сахарного диабета с наличием кетоацидоза/осмотической дегидратации.

\section{Условия проведения}

Исследование проводилось на базе эндокринологической клиники ФГБОУ ВО СибГМУ г. Томска. В исследование включались пациенты, находящиеся на плановой госпитализации в эндокринологической клинике ФГБОУ ВО СибГМУ г. Томска.

\section{Продолжительность исследования}

Набор пациентов в исследование проводился в течение двух лет (2017-2019 гг.).

\section{Описание медицинского вмешательства}

У всех включенных в исследование пациентов проводились сбор анамнестических данных, оценка антропометрических данных, а также забор венозной крови утром натощак из локтевой вены. У пациентов основной группы проводился забор утренней порции мочи с определением микроальбуминурии. В полученных образцах крови исследовались гликированный гемоглобин - в качестве основного параметра оценки компенсации углеводного обмена, уровень креатинина крови с последующим расчетом скорости клубочковой фильтрации по формуле CKD-EPI, оценивались основные гематологические показатели (количество эритроцитов, ретикулоцитов, концентрация гемоглобина, уровень гематокрита) и биохимические показатели обмена железа - концентрация сывороточного железа, трансферрина и ферритина. Также среди всех включенных в исследование пациентов проводилась оценка маркеров воспаления - скорости оседания эритроцитов (СОЭ), высокочувствительного С-реактивного белка (СРБ) и фактора некроза опухолей-а (ФНО-а), и показателей липидного спектра (общий холестерин, лПВП-холестерин, ЛПНП-холестерин, лПОНП-холестерин, триглицериды).

\section{Методы регистрации исходов}

Материалом исследования являлись плазма и сыворотка венозной крови, взятые утром натощак из локтевой вены в количестве 10 мл в вакуумные пробирки BD Vacutainer. Исследование гликированного гемоглобина проводилось с использованием анализатора D10 («BIO-RAD», США); исследование микроальбуминурии (мг/л) - с использованием анализатора Abbott Architect c4000. Для оценки основных гематологических показателей (количество эритроцитов, ретикулоцитов, концентрация гемоглобина, уровень гематокрита) использовался гематологический анализатор XN1000 («Sysmex», Япония). Для оценки уровня креатинина и биохимических показателей обмена железа, а именно - концентрации сывороточного железа (мкмоль/л), трансферрина (мг/дл) и ферритина (нг/мл) - использовался анализатор ARCHITECT i2000SR (Abbott, США). Показатели липидного спектра (общий холестерин, ЛПВП-холестерин, ЛПНП-холестерин, ЛПОНП-холестерин, триглицериды) (ммоль/л) исследовались на анализаторе ARCHITECT i2000SR (Abbott, CША). Оценка СОЭ проводилась гематологическим анализатором XN1000 (Sysmex, Япония), высокочувствительного СРБ (нг/мл) - методом ИФА («Вектор Бест», Россия), исследование ФНО-а (пг/мл) также проводилось методом ИФА («Вектор Бест», Россия). Диагноз анемии устанавливался в соответствии с Федеральными клиническими рекомендациями по диагностике и лечению железодефицитной анемии (Румянцев А.Г., Масчан А.А. и др., 2015 г.) [18] и Федеральными клиническими рекомендациями по диагностике и лечению анемии хронических болезней (Румянцев А.Г., Масчан А.А., 2014 г.) 19]. Тип дислипидемии определялся по классификации D. Fredrickson (1967) [20].

\section{Исходы исследования}

В рамках задач проведенной работы планировалось исследовать и сравнить основные гематологические и биохимические показатели обмена железа, а именно количество эритроцитов, ретикулоцитов, концентрация гемоглобина, уровень гематокрита, концентрацию железа сыворотки, ферритина и трансферрина - у лиц в зависимости от наличия и типа сахарного диабета. Также планировалось в сравнительном аспекте изучить концентрации маркеров воспаления, таких как СОЭ, высокочувствительный СРБ и ФНО-а у пациентов с сахарным диабетом 1 и 2 типа и лиц с ожирением. Одной из задач являлась оценка состояния липидного обмена и установление фенотипов дислипидемии в зависимости от типа сахарного диабета. В результате исследования планировалось установить направленность изменений воспалительного статуса и состояния феррокинетики у пациентов с сахарным диабетом 1 и 2 типов в зависимости от типа нарушений липидного обмена.

\section{Анализ в подгруппах}

Все включенные в исследование пациенты были разделены в четыре группы. Основная группа была разделена в зависимости от типа сахарного диабета на основную группу 1 (пациенты с сахарным диабетом 1 типа) и основную группу 2 (пациенты с сахарным диабетом 2 типа). Дополнительная группа была разделена на группу сравнения и контроля зависимости от индекса массы тела (ИМТ): в группу сравнения вошли пациенты с ожирением 
без нарушений углеводного обмена, в группу контроля были включены здоровые добровольцы, не имевшие ожирения и нарушений углеводного обмена.

\section{Этическая экспертиза}

Протокол исследования был одобрен локальным этическим комитетом ФГБОУ ВО СибГМУ Минздрава России, номер протокола 5596 от 06.11.2017 г. Все включенные в исследование пациенты подписали добровольное информированное согласие.

\section{Статистический анализ}

Принципы расчета размера выборки: С целью установления объема выборки, использовалась последовательная стратегия расчёта объема выборки с учетом коэффициента вариации (=среднеквадратичное отклонение от среднеарифметического в \%), по результатам которой необходимый объем выборки для каждой из основных групп составил от 61 человека.

Методы статистического анализа данных: Статистическая обработка результатов осуществлялась с использованием пакета программ SPSS Statistics 23. Проверка нормальности распределения проводилась по критерию Колмагорова-Смирнова. Пороговый уровень значимости (р) был принят равным 0,05. Нормальному закону распределения подчинялись следующие параметры: гликированный гемоглобин, СКФ, трансферрин, гематокрит и количество эритроцитов. Остальные параметры, а именно: возраст, длительность заболевания диабетом, ИМТ, микроальбуминурия, креатинин крови, СРБ, ФНО-а, СОЭ, железо, ферритин, гемоглобин, ретикулоциты, лейкоциты, АСТ, АЛТ, общий холестерин, ЛПВП, ЛПНП, ЛПОНП и триглицериды не подчинялись нормальному закону распределения. С целью унификации представления данных, все результаты были представлены в виде ме- дианы и интерквартильного размаха (Me, Q0,25-Q0,75). В целях установления значимости различий показателей между независимыми группами сравнения была проведена статистическая обработка с помощью критерия Манна-Уитни с использованием поправки Бонеферрони для четырех групп, пороговый уровень значимости был принят равным p<0,013. Для показателей, имевших нормальное распределение, проводилась статистическая обработка с помощью критерия Стьюдента. Статистическую значимость различий частоты встречаемости качественных признаков в анализируемых группах проверяли с помощью критерия $\mathrm{X}^{2}$ Пирсона с критическим уровнем значимости $\mathrm{p}<0,05$.

\section{РЕЗУЛЬТАТЫ}

Объекты (участники) исследования

В исследование вошли 157 человек: 48 человек с сахарным диабетом 1, 81 пациент с сахарным диабетом 2 типа, 11 пациентов с ожирением, но без НУО и 17 здоровых добровольцев с нормальным ИМТ и без патологии углеводного обмена.

Среди лиц с сахарным диабетом было 43 мужчины $(33,3 \%)$ и $86(66,7 \%)$ женщин. Внутри основных групп соотношение мужчин и женщин было сопоставимым: в группе пациентов с сахарным диабетом 1 типа было 19 (39,6\%) мужчин и 29 (60,4\%) женщин, в группе пациентов с сахарным диабетом 2 типа - 24 (29,6\%) мужчины и 57 (70,4\%) женщин $\left(x^{2}=1,276 ; p=0,259\right)$. В группе сравнения количество мужчин и женщин было практически равным: 5 мужчин (45,5\%) и 6 женщин (54,5\%). В группе здорового контроля, как и в основных группах, мужчин было меньше, чем женщин: 4 (23,5\%) и 13 (76,5\%) соответственно.

В таблице 1 приведена клиническая характеристика групп исследования.

Таблица 1. Клиническая характеристика групп.

\begin{tabular}{|c|c|c|c|c|}
\hline Показатель & $\begin{array}{c}\text { Сахарный диабет } 1 \\
\text { типа } \\
\mathbf{n}=48\end{array}$ & $\begin{array}{c}\text { Сахарный диабет } 2 \\
\text { типа } \\
\mathbf{n = 8 1}\end{array}$ & $\begin{array}{c}\text { Ожирение без НУО } \\
n=11\end{array}$ & $\begin{array}{c}\text { Группа контроля } \\
\text { (здоровые) } \\
\text { n=17 }\end{array}$ \\
\hline Возраст, лет & $\begin{array}{c}34,00 \\
{[26,00-52,00]}\end{array}$ & $\begin{array}{c}60,00 \\
{[56,00-65,00]^{*}}\end{array}$ & $\begin{array}{c}37,00 \\
{[25,00-49,00]^{\#}}\end{array}$ & $\begin{array}{c}40,00 \\
{[32,00-58,00]^{\#}}\end{array}$ \\
\hline Стаж заболевания, лет & $\begin{array}{c}9,00 \\
{[3,00-17,00]}\end{array}$ & $\begin{array}{c}11,00 \\
{[8,00-15,00]}\end{array}$ & - & - \\
\hline ИМТ, кг/М кВ. & $\begin{array}{c}23,67 \\
{[21,43-26,03]}\end{array}$ & $\begin{array}{c}33,80 \\
{[29,55-38,82]^{*}}\end{array}$ & $\begin{array}{c}36,39 \\
{[30,80-38,35]^{*}}\end{array}$ & $\begin{array}{c}25,10 \\
{[23,10-27,65]^{\# \prime \prime}}\end{array}$ \\
\hline OT, сM & $\begin{array}{c}86,34 \\
{[74,43-92,33]}\end{array}$ & $\begin{array}{c}106,64 \\
{[96,68-114,54]}\end{array}$ & $\begin{array}{c}108,72 \\
{[99,11-118,24]}\end{array}$ & $\begin{array}{c}79,34 \\
{[71,22-86,43]}\end{array}$ \\
\hline $\mathrm{HbA}_{1 \mathrm{c}^{\prime}} \%$ & $\begin{array}{c}8,80 \\
{[6,95-10,30]}\end{array}$ & $\begin{array}{c}9,10 \\
{[7,97-11,03]}\end{array}$ & $\begin{array}{c}5,30 \\
{[4,93-5,80]^{* \#}}\end{array}$ & $\begin{array}{c}5,20 \\
{[4,90-5,85]^{* \#}}\end{array}$ \\
\hline СКФ, мл/мин & $\begin{array}{c}95,00 \\
{[71,75-112,75]}\end{array}$ & $\begin{array}{c}80,50 \\
{[63,00-93,00]^{*}}\end{array}$ & $\begin{array}{c}102,50 \\
{[97,50-115,25]^{\#}}\end{array}$ & $\begin{array}{c}96,50 \\
{[93,00-106,00]^{\#}}\end{array}$ \\
\hline МАУ, мг/л & $\begin{array}{c}20,50 \\
{[9,25-39,25]}\end{array}$ & $\begin{array}{c}13,55 \\
{[8,53-30,00]}\end{array}$ & - & - \\
\hline АСТ, ЕД/л & $\begin{array}{c}20,00 \\
{[16,60-27,00]}\end{array}$ & $\begin{array}{c}19,40 \\
{[15,00-28,00]}\end{array}$ & $\begin{array}{c}23,00 \\
{[14,00-29,00]}\end{array}$ & $\begin{array}{c}20,00 \\
{[16,50-22,50]}\end{array}$ \\
\hline АЛТ, ЕД/л & $\begin{array}{c}16,00 \\
{[12,00-24,00]}\end{array}$ & $\begin{array}{c}20,00 \\
{[14,00-29,75]^{*}}\end{array}$ & $\begin{array}{c}25,00 \\
{[16,00-42,00]^{*}}\end{array}$ & $\begin{array}{c}18,00 \\
{[11,50-21,00]}\end{array}$ \\
\hline
\end{tabular}

Примечание. * - достоверность различий по сравнению с аналогичными показателями в группе 1 (р<0,013); \# - достоверность различий по сравнению с аналогичными показателями в группе 2; - достоверность различий по сравнению с аналогичными показателями в группе 3. Данные представлены в виде Ме [Q0,25-Q0,75]. 
Таблица 2. Структура ожирения.

\begin{tabular}{lccccc}
\hline \multicolumn{1}{c}{$\begin{array}{c}\text { Наличие, степень } \\
\text { ожирения }\end{array}$} & $\begin{array}{c}\text { Общая } \\
\text { выборка } \\
\text { (n=157) }\end{array}$ & $\begin{array}{c}\text { Сахарный } \\
\text { диабет 1 типа } \\
\text { (n=48) }\end{array}$ & $\begin{array}{c}\text { Сахарный } \\
\text { диабет 2 типа } \\
\text { (n=81) }\end{array}$ & $\begin{array}{c}\text { Ожирение без } \\
\text { нуо (n=11) }\end{array}$ & $\begin{array}{c}\text { Группа } \\
\text { контроля } \\
\text { (3доровые) }\end{array}$ \\
\hline Нет ожирения, \% (n) & $27,6(43)$ & $62,7(30)$ & $3,6(3)$ & $0(0)$ & $58,8(10)$ \\
Избыточная масса тела, \% (n) & $23,9(38)$ & $27,5(13)$ & $21,4(17)$ & $0(0)$ & $41,2(7)$ \\
Ожирение 1 степени, \% (n) & $19,6(31)$ & $7,8(4)$ & $27,4(22)$ & $36,4(4)$ \\
Ожирение 2 степени, \% (n) & $17,2(27)$ & $2,0(1)$ & $27,4(22)$ & $0(0)$ \\
Ожирение 3 степени, \% (n) & $11,7(18)$ & $0(0)$ & $20,2(17)$ & $18,2(2)$ \\
\hline
\end{tabular}

Как видно из представленных в таблице 1 данных, основные группы 1 и 2 были сопоставимы по стажу заболевания диабетом, уровню гликированного гемоглобина и микроальбуминурии. При этом, пациенты с сахарным диабетом 2 типа имели ИМТ значимо выше, чем у пациентов с сахарным диабетом 1 типа $(p<0,0001)$ и выше, чем у лиц группы контроля ( $<<0,0001)$. Характеристика структуры ожирения в исследуемых группах пациентов приведена в таблице 2. Как видно из представленных в таблице данных, ожирение у пациентов с сахарным диабетом 2 типа встречалось значимо чаще, чем у пациентов с сахарным диабетом 1 типа $\left(x^{2}=71,257 ; p<0,0001\right)$. При этом в структуре ожирения у лиц с сахарным диабетом 2 типа преобладало ожирение 1 и 2 степени, а у пациентов с сахарным диабетом 1 типа ожирение встречалось только в 9,8\% случаев. Уровень СКФ у пациентов с сахарным диабетом 2 типа был ниже, чем у пациентов с сахарным диабетом 1 типа $(p=0,006)$, пациентов с ожирением ( $<<0,0001)$ и здоровых добровольцев $(p<0,0001)$. Уровень гликированного гемоглобина как у лиц группы контроля, так и у пациентов с ожирением был значимо ниже, чем у пациентов с сахарным диабетом 1 и 2 типа ( $p<0,0001$ во всех случаях).

Среди всех пациентов с сахарным диабетом 94 человека (72,8\%) на момент включения в исследование страдали гипертонической болезнью. Из них 13 человек $(13,8 \%)$ не получали гипотензивную терапию, остальные 81 пациент (86,2\%) получали от 1 до 4 антигипертензивных препаратов. В группе сравнения 4 пациента $(36,4 \%)$ также страдали гипертонической болезнью, но ни один из них антигипертензивной терапии не получал. Пациенты группы контроля гипертонической болезнью не страдали.

\section{Основные результаты исследования}

В результате сравнительного анализа состояния воспалительного статуса в указанных группах было установлено, что содержание в крови ФНО-а было значимо выше у пациентов с сахарным диабетом 1 типа в сравнении как с пациентами с сахарным диабетом 2 типа $(p<0,0001)$, так и с лицами группы сравнения $(p=0,003)$ и контроля $(p=0,004)$. При этом в группе пациентов с сахарным диабетом 2 типа была значимо выше концентрация СРБ, чем у пациентов с сахарным диабетом 1 типа ( $p<0,0001)$. У лиц групп сравнения и контроля сывороточное содержание СРБ по техническим причинам определено не было. Стоит отметить, что при сахарном диабете 2 типа уровень СОЭ был также достоверно выше, чем при сахарном диабете 1 типа ( $p<0,0001)$, ожирении без НУО $(p=0,013)$ и контрольной группе ( $<<0,0001)$. Параметры воспаления значимо не различались у пациентов с ожирением и у здоровых добровольцев.

Были выявлены значимые различия в содержании ферритина - данный параметр был достоверно выше у пациентов с сахарным диабетом 2 типа, чем у пациентов с сахарным диабетом 1 типа ( $p=0,013)$, а также достоверно выше у лиц с ожирением, чем при 1 типе диабета ( $p=0,013)$. Между остальными параметрами обмена железа в указанных группах значимых различий выявлено не было. Результаты сравнительной оценки воспалительного статуса и феррокинетики приведены в таблице 3.

На основании результатов исследования параметров обмена железа (гемоглобин, железо сыворотки, ферритин) был установлен тип нарушения феррокинетики для всех включенных в исследование лиц (латентный дефицит железа, железодефицитная анемия, анемия хронических заболеваний). Стоит отметить, что в 2 из 157 случаев имели место признаки дисметаболической перегрузки железом, а именно: повышение содержания ферритина выше 300 нг/мл и железа сыворотки выше референтных значений. Данные случаи имели место в группе пациентов с сахарным диабетом 2 типа и в группе пациентов с ожирением без НУО. Однако выделить данные случаи в отдельную группу перегрузки железом не представлялось возможным ввиду отсутствия достаточного количества критериев диагностики: насыщение трансферрина железом и общая железосвязывающая способность сыворотки не исследовались. Частота диагностики латентного дефицита железа и анемии приведена в таблице 4.

Среди всех включенных в исследование лиц $(\mathrm{n}=157)$ дислипидемия была выявлена в 79\% случаев $(\mathrm{n}=124)$, при этом стоит отметить, что в группе здоровых добровольцев дислипидемии выявлено не было. Среди пациентов с сахарным диабетом 1 типа частота дислипидемии составила 83,3\%, а в группе пациентов с сахарным диабетом 2 типа - 95,1\%. У пациентов с ожирением без нарушений углеводного обмена дислипидемия была выявлена 
Таблица 3. Параметры воспалительного статуса и обмена железа.

\begin{tabular}{|c|c|c|c|c|}
\hline Показатель & $\begin{array}{c}\text { Сахарный диабет } \\
1 \text { типа }\end{array}$ & $\begin{array}{c}\text { Сахарный диабет } \\
2 \text { типа }\end{array}$ & Ожирение без НУО & $\begin{array}{c}\text { Группа контроля } \\
\text { (здоровые) }\end{array}$ \\
\hline ФНО-а, пг/мл & $\begin{array}{c}15,28 \\
{[12,41-24,41]}\end{array}$ & $\begin{array}{c}8,54 \\
{[6,27-11,60]^{*}}\end{array}$ & $\begin{array}{c}9,83 \\
{[5,89-14,58]^{*}}\end{array}$ & $\begin{array}{c}9,68 \\
{[5,68-15,38]^{*}}\end{array}$ \\
\hline СРБ, нг/мл & $\begin{array}{c}2,00 \\
{[1,05-4,05]}\end{array}$ & $\begin{array}{c}7,00 \\
{[3,00-11,85]^{*}}\end{array}$ & - & - \\
\hline СОЭ, мм/ч & $\begin{array}{c}14,00 \\
{[5,00-21,25]}\end{array}$ & $\begin{array}{c}18,00 \\
{[9,00-27,00]^{*}}\end{array}$ & $\begin{array}{c}10,00 \\
{[5,00-17,00]^{\#}}\end{array}$ & $\begin{array}{c}7,00 \\
{[5,00-9,00]^{\#}}\end{array}$ \\
\hline Лейкоциты, $\times 10^{9} / л$ & $\begin{array}{c}6,55 \\
{[5,30-7,83]}\end{array}$ & $\begin{array}{c}7,38 \\
{[6,08-8,74]}\end{array}$ & $\begin{array}{c}7,59 \\
{[5,51-8,32]}\end{array}$ & $\begin{array}{c}6,08 \\
{[5,25-7,53]}\end{array}$ \\
\hline Гемоглобин, г/л & $\begin{array}{c}138,50 \\
{[122,50-151,00]}\end{array}$ & $\begin{array}{c}141,00 \\
{[125,25-151,00]}\end{array}$ & $\begin{array}{c}150,00 \\
{[138,00-159,00]}\end{array}$ & $\begin{array}{c}146,00 \\
{[135,00-150,00]}\end{array}$ \\
\hline Эритроциты, ×10²/л & $\begin{array}{c}4,69 \\
{[4,38-5,09]}\end{array}$ & $\begin{array}{c}4,79 \\
{[4,39-5,19]}\end{array}$ & $\begin{array}{c}5,24 \\
{[4,60-5,44]}\end{array}$ & $\begin{array}{c}4,80 \\
{[4,49-5,02]}\end{array}$ \\
\hline Ретикулоциты, \% & $\begin{array}{c}1,51 \\
{[1,12-1,75]}\end{array}$ & $\begin{array}{c}1,76 \\
{[1,54-1,91]}\end{array}$ & $\begin{array}{c}1,53 \\
{[1,20-2,27]}\end{array}$ & $\begin{array}{c}1,60 \\
{[1,40-1,66]}\end{array}$ \\
\hline Гематокрит, \% & $\begin{array}{c}40,95 \\
{[38,40-43,65]}\end{array}$ & $\begin{array}{c}42,05 \\
{[38,00-44,55]}\end{array}$ & $\begin{array}{c}43,95 \\
{[41,45-47,73]}\end{array}$ & $\begin{array}{c}42,70 \\
{[40,70-44,85]}\end{array}$ \\
\hline Железо, мкмоль/л & $\begin{array}{c}12,00 \\
{[8,00-17,00]}\end{array}$ & $\begin{array}{c}13,00 \\
{[11,00-18,25]}\end{array}$ & $\begin{array}{c}19,00 \\
{[11,75-23,25]}\end{array}$ & $\begin{array}{c}16,00 \\
{[11,00-20,50]}\end{array}$ \\
\hline Ферритин, нг/мл & $\begin{array}{c}44,48 \\
{[18,35-148,50]}\end{array}$ & $\begin{array}{c}96,52 \\
{[42,93-189,70]^{*}}\end{array}$ & $\begin{array}{c}97,60 \\
{[21,70-445,60]^{*}}\end{array}$ & $\begin{array}{c}72,05 \\
{[43,23-148,60]}\end{array}$ \\
\hline Трансферрин, мг/дл & $\begin{array}{c}284,00 \\
{[250,00-334,00]}\end{array}$ & $\begin{array}{c}293,00 \\
{[267,00-321,50]}\end{array}$ & $\begin{array}{c}270,00 \\
{[207,00-346,00]}\end{array}$ & $\begin{array}{c}267,50 \\
{[208,75-306,50]}\end{array}$ \\
\hline рТФР, нг/мл & $\begin{array}{c}136,72 \\
{[119,85-157,09]}\end{array}$ & $\begin{array}{c}121,01 \\
{[113,74-141,95]}\end{array}$ & $\begin{array}{c}117,52 \\
{[109,38-121,59]}\end{array}$ & $\begin{array}{c}116,36 \\
{[107,05-119,85]}\end{array}$ \\
\hline Гепсидин, пг/мл & $\begin{array}{c}9798,00 \\
{[3737,00-12667,00]}\end{array}$ & $\begin{array}{c}7697,00 \\
{[3434,50-11454,50]}\end{array}$ & - & - \\
\hline
\end{tabular}

Примечание. * - достоверность различий по сравнению с аналогичными показателями в группе 1 (р<0,013); \# - достоверность различий по сравнению с аналогичными показателями в группе 2; “ достоверность различий по сравнению с аналогичными показателями в группе 3. Данные представлены в виде Ме [Q0,25-Q0,75].

Таблица 4. Структура анемического синдрома.

\begin{tabular}{|c|c|c|c|c|c|}
\hline & $\begin{array}{c}\text { общая } \\
\text { выборка } \\
\text { (n=157) }\end{array}$ & $\begin{array}{c}\text { Сахарный } \\
\text { диабет } 1 \text { типа } \\
(n=48)\end{array}$ & $\begin{array}{c}\text { Сахарный } \\
\text { диабет } 2 \text { типа } \\
(\mathbf{n = 8 1 )}\end{array}$ & $\begin{array}{c}\text { Ожирение без } \\
\text { НуО (n=11) }\end{array}$ & $\begin{array}{c}\text { Группа } \\
\text { контроля } \\
\text { (здоровые) } \\
(n=17)\end{array}$ \\
\hline Нет анемии, \% (n) & $51,0(80)$ & $43,8(21)$ & $50,6(41)$ & $54,5(6)$ & $70,6(12)$ \\
\hline $\begin{array}{l}\text { Латентный дефицит } \\
\text { железа, \% (n) }\end{array}$ & $28,7(45)$ & $27,1(13)$ & $30,9(25)$ & $18,2(2)$ & 29,4 (5) \\
\hline $\begin{array}{l}\text { Железодефицитная } \\
\text { анемия, \% (n) }\end{array}$ & $9,6(15)$ & $16,7(8)$ & $7,4(6)$ & $9,1(1)$ & $0(0)$ \\
\hline $\begin{array}{l}\text { Анемия хронических } \\
\text { заболеваний, \% (n) }\end{array}$ & $9,6(15)$ & $12,5(6)$ & $9,9(8)$ & $9,1(1)$ & $0(0)$ \\
\hline
\end{tabular}


Таблица 5. Частота встречаемости дислипидемии в общей выборке и в отдельных группах пациентов.

\begin{tabular}{lccccc}
\hline & $\begin{array}{c}\text { Общая } \\
\text { выборка } \\
\text { (n=157) }\end{array}$ & $\begin{array}{c}\text { Сахарный } \\
\text { диабет 1 типа } \\
(\mathbf{n = 4 8 )}\end{array}$ & $\begin{array}{c}\text { Сахарный } \\
\text { диабет 2 типа } \\
(\mathbf{n = 8 1 )}\end{array}$ & $\begin{array}{c}\text { Ожирение } \\
\text { без НУО } \\
(\mathbf{n}=\mathbf{1 1 )}\end{array}$ & $\begin{array}{c}\text { Группа контроля } \\
\text { (3доровые) } \\
\text { (n=17) }\end{array}$ \\
\hline Дислипидемия, \% (n) & $79(124)$ & $83,3(40)$ & $95,1(77)$ & $63,6(7)$ & $0,0(0)$ \\
Нет дислипидемии, \% (n) & $21(33)$ & $16,7(8)$ & $4,9(4)$ & $36,4(4)$ & $100,0(17)$ \\
\hline
\end{tabular}

Рисунок 1. Частота встречаемости дислипидемии

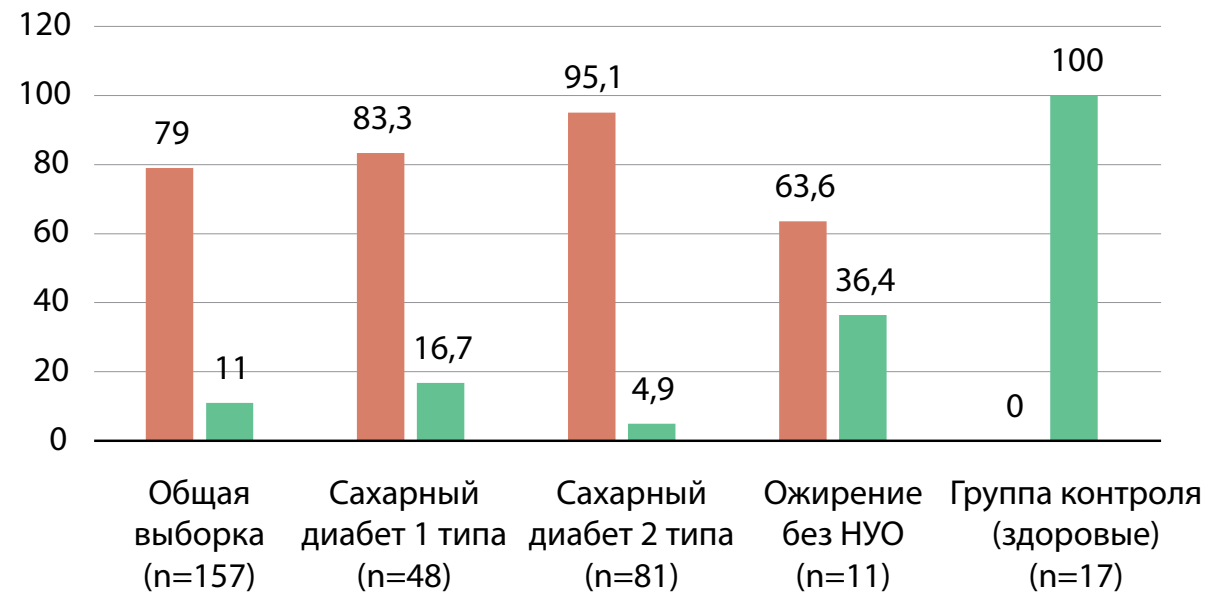

Дислипидемия, \%

Нет дислипидемии, \%

в 63,6\% случаев (табл. 5, рис. 1). Частота встречаемости дислипидемии в общей выборке и в отдельных группах пациентов представлена в таблице 5 и на рисунке 1.

Кроме того, было установлено, что в общей когорте пациентов с дислипидемией $(\mathrm{n}=124)$ преобладали пациенты с сахарным диабетом 2 типа (рис. 2),

Дислипидемия $(\mathrm{n}=124)$

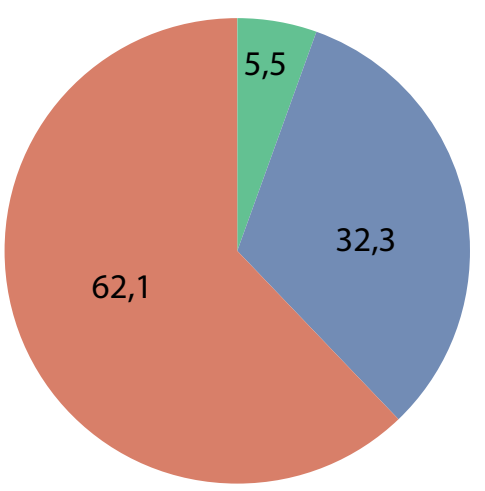

Ожирение, \%

Сахарный диабет 1 типа, \%

Сахарный диабет 2 типа, \%

Рисунок 2. Структура дислипидемии в зависимости от типа метаболических нарушений. что подтверждает вклад в развитие и прогрессирование нарушений липидного обмена как функциональной активности жировой ткани, так и дисгликемии.

Среди всех пациентов с дислипидемией $(\mathrm{n}=124)$ липид-корригирующую терапию на момент включения в исследование получали только $25,8 \%$ пациентов $(n=32)$, тогда как остальные $74,2 \%$ человек $(n=92)$ никаких препаратов, направленных на коррекцию липидного обмена, не принимали. Стоит отметить, что все принимавшие липид-корригирующие препараты получали препараты из группы статинов. В группе пациентов с сахарным диабетом 1 типа и дислипидемией частота приема статинов составила $12,5 \%(n=5)$, в группе пациентов с сахарным диабетом 2 типа - 35,1\% ( $=27)$, среди пациентов с ожирением без патологии углеводного обмена ни один человек статины не принимал (табл. 6). Как видно из представленных данных, в целом приверженность пациентов к липид-корригирующей терапии была достаточно низкой.

Среди пациентов с дислипидемией, не принимавших на момент включения в исследование препаратов, направленных на коррекцию нарушений липидного обмена (n=91), был проведен анализ типов дислипидемии по классификации D. Fredrickson [3],

Таблица 6. Частота приема статинов у лиц с дислипидемией в общей выборке и в отдельных группах пациентов.

\begin{tabular}{lcccc}
\hline & $\begin{array}{c}\text { Общая выборка } \\
\text { (n=124) }\end{array}$ & $\begin{array}{c}\text { Сахарный диабет } \\
\text { 1 типа (n=40) }\end{array}$ & $\begin{array}{c}\text { Сахарный диабет } \\
\text { 2 типа (n=77) }\end{array}$ & $\begin{array}{c}\text { Ожирение без НУО } \\
\text { (n=7) }\end{array}$ \\
\hline Принимали статины, \% (n) & $25,8(32)$ & $12,5(5)$ & $35,1(27)$ & $0(0)$ \\
Не принимали статины, \% (n) & $74,2(92)$ & $87,5(35)$ & $64,9(50)$ & $100,0(7)$ \\
\hline
\end{tabular}


Таблица 7. Характеристика дислипидемии по классификации D. Fredrickson [20] в общей выборке лиц и в отдельных группах пациентов.

\begin{tabular}{lcccc}
\hline & $\begin{array}{c}\text { Общая } \\
\text { выборка } \\
\text { (n=91) }\end{array}$ & $\begin{array}{c}\text { Сахарный диабет } \\
\mathbf{1} \text { типа } \\
(\mathbf{n = 3 5 )}\end{array}$ & $\begin{array}{c}\text { Сахарный диабет } \\
\mathbf{2} \text { типа } \\
\text { (n=50) }\end{array}$ & $\begin{array}{c}\text { Ожирение } \\
\text { 6ез НУо } \\
\text { (n=6) }\end{array}$ \\
\hline Дислипидемия Ila типа, \% (n) & $45,1(41)$ & $77,1(27)$ & $22,0(11)$ & $50,0(3)$ \\
Дислипидемия IIb, типа, \% (n) & $54,9(50)$ & $22,9(8)$ & $78,0(39)$ & $50,0(3)$ \\
\hline
\end{tabular}

Рисунок 3. Характеристика дислипидемии по классификации D. Fredrickson [20] в общей выборке лиц и в отдельных группах пациентов

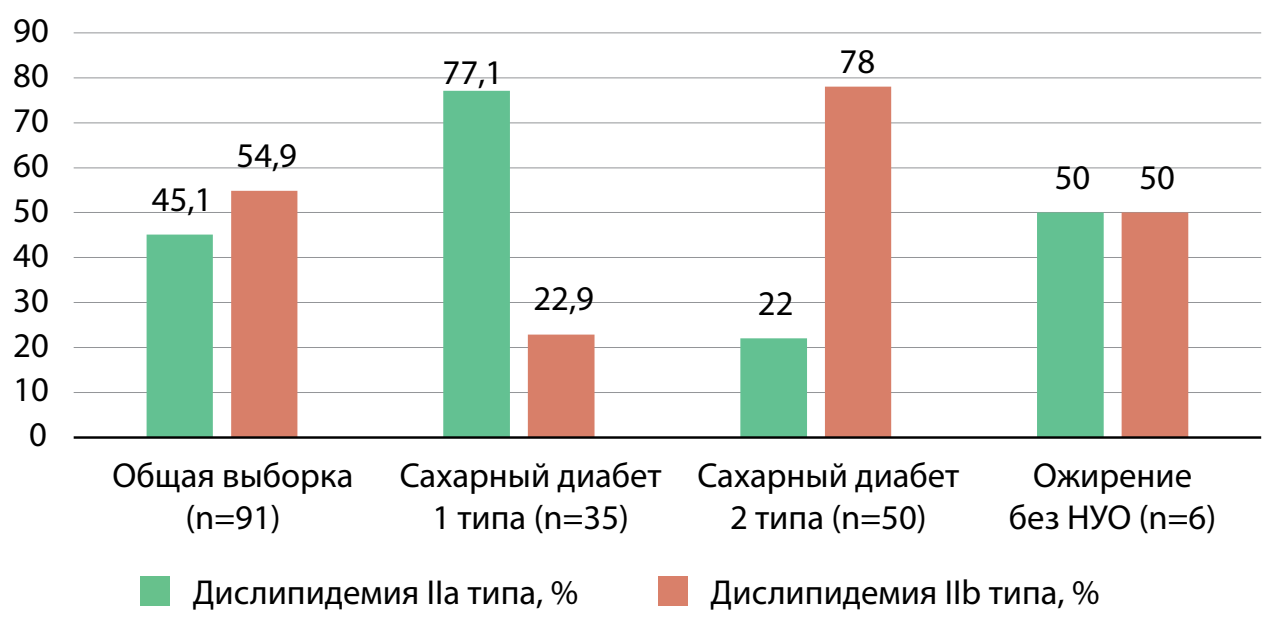

результат анализа представлен в таблице 7 и на рисунке 3.

Таким образом, в группе пациентов с сахарным диабетом 2 типа преобладал наиболее атерогенный тип дислипидемии, в то время как у пациентов с ожирением различий в частоте встречаемости дислипидемии типа Ila и типа IIb выявлено не было, а у пациентов с сахарным диабетом 1 типа чаще встречался менее атерогенный фенотип дислипидемии $\left(x^{2}=34,051 ; p<0,0001\right)$.

Были выявлены значимые различия отдельных показателей липидного спектра в зависимости от наличия и вида сахарного диабета. Так, у пациентов с сахарным диабетом 2 типа были достоверно выше уровни ЛПОНП-холестерина $(p<0,0001)$, триглицеридов $(p<0,0001)$, и коэффициент атерогенности ( $<<0,0001)$, а уровень ЛПВП-холестерина значимо ниже $(p<0,0001)$ в сравнении с аналогичными показателями в группе пациентов с сахарным диабетом 1 типа (табл. 7). Кроме того, показатели ЛПОНП-холестерина и триглицеридов при сахарном диабете 2 типа были выше в сравнении с таковыми у пациентов с ожирением, но без нарушений углеводного обмена ( $p=0,040$ и $p=0,019$ соответственно) (табл. 8). При этом не наблюдалось значимых различий между содержанием компонентов холестерина у пациентов с сахарным диабетом 1 типа и пациентов с ожирением без диабета, а также пациентов группы здорового контроля (табл. 8). Сравнительная характеристика параметров липидного спектра в указанных группах представлена в таблице 8.

Таблица 8. Сравнительная характеристика параметров липидного спектра.

\begin{tabular}{lcccc}
\hline & $\begin{array}{c}\text { Сахарный диабет 1 } \\
\text { типа }(\mathbf{n = 4 8 )}\end{array}$ & $\begin{array}{c}\text { Сахарный диабет 2 } \\
\text { типа }(\mathbf{n = 8 1 )}\end{array}$ & $\begin{array}{c}\text { Ожирение без НУо } \\
\text { (n=11) }\end{array}$ & $\begin{array}{c}\text { Группа контроля } \\
\text { (здоровые) (n=17) }\end{array}$ \\
\hline Общий холестерин, & 4,98 & 5,41 & 5,00 & 4,90 \\
ммоль/л & {$[4,33-5,68]$} & {$[4,58-6,40]$} & {$[4,60-6,00]$} & $14,50-5,35]$ \\
ЛПВП-холестерин, & 1,50 & 1,04 & 1,25 & 1,60 \\
ммоль/л & {$[1,23-1,84]$} & {$[0,90-1,30]^{*}$} & {$[1,03-1,50]$} & {$[1,33-1,90]^{* *}$} \\
ЛПнП-холестерин, & 2,95 & 3,25 & 2,95 & 3,00 \\
ммоль/л & {$[2,55-3,28]$} & {$[2,28-4,00]$} & {$[2,63-3,61]$} & {$[2,25-3,24]^{* *}$} \\
ЛПОНП-холестерин, & 0,50 & 1,00 & 0,68 & 0,41 \\
ммоль/л & {$[0,36-0,68]$} & {$[0,73-1,31]^{*}$} & {$[0,55-0,98]^{* *}$} & {$[0,29-0,70]^{* *}$} \\
Триглицериды, & 1,05 & 2,20 & 1,45 & 0,90 \\
ммоль/л & {$[0,73-1,58]$} & {$[1,60-2,70]^{*}$} & {$[1,25-2,13]^{* *}$} & {$[0,65-1,45]^{* *}$} \\
Коэффициент & 2,38 & 4,00 & 3,20 & 2,30 \\
атерогенности & {$[1,80-3,83]$} & {$[2,95-5,11]^{*}$} & {$[2,15-4,50]$} & {$[1,88-2,85]^{* *}$} \\
\hline
\end{tabular}

Примечание. * - достоверность различий по сравнению с аналогичными показателями у пациентов с сахарным диабетом 1 типа (р<0,013); ** - достоверность различий по сравнению с аналогичными показателями у пациентов с сахарным диабетом 2 типа. Данные представлены в виде Me $[\mathrm{Q} 0,25-\mathrm{Q} 0,75]$. 
Среди пациентов с сахарным диабетом и дислипидемией $(n=117)$ был проведен сравнительный анализ между маркерами неспецифического воспаления и параметрами феррокинетики в зависимости от типа дислипидемии и независимо от факта приема статинов. Результаты анализа представлены в таблице 9.

Как видно из представленной таблицы, у пациентов с сахарным диабетом и дислипидемией Ilb уровень таких воспалительных маркеров, как СРБ, СОЭ и ферритин был значимо выше, чем у пациентов с сахарным диабетом и менее атерогенной дислипидемией Ila типа. При этом содержание в крови ФНО-а и концентрация гепсидина, обычно повышенные в условиях воспаления, было выше у пациентов с дислипидемией Ila типа.
Поскольку в структуре дислипидемии при сахарном диабете 1 типа преобладала дислипидемия Ila, а при сахарном диабете 2 типа - дислипидемия Ilb, с целью уточнения степени влияния типа дислипидемии и типа сахарного диабета на состояние воспалительного статуса, был проведен анализ параметров воспалительного ответа во вновь сформированных подгруппах, где выбраны пациенты с сахарным диабетом 1 и 2 типа и минорным для данного типа диабета вариантом дислипидемии. Таким образом сформированы следующие подгруппы: 1) сахарный диабет 1 типа в сочетании с IIb дислипидемией 2) сахарный диабет 2 типа в сочетании c Ila дислипидемией. Результаты данного субанализа приведены в таблице 10.

Таблица 9. Характеристика воспалительного статуса и состояния обмена железом у пациентов с сахарным диабетом в зависимости от типа дислипидемии.

\begin{tabular}{|c|c|c|}
\hline Показатель & Дислипидемия IIa типа & Дислипидемия IIb типа \\
\hline ФНО-а, пг/мл & $\begin{array}{c}13,21 \\
{[9,15-24,02]}\end{array}$ & $\begin{array}{c}9,78 \\
{[7,15-13,92]^{*}}\end{array}$ \\
\hline СРБ, нг/мл & $\begin{array}{c}3,00 \\
{[1,80-8,70]}\end{array}$ & $\begin{array}{c}6,9 \\
{[3,00-12,35]^{*}}\end{array}$ \\
\hline СОЭ, мм/час & $\begin{array}{c}15,00 \\
{[5,00-24,50]}\end{array}$ & $\begin{array}{c}20,00 \\
{[10,00-30,00]^{*}}\end{array}$ \\
\hline Лейкоциты, ×109/л & $\begin{array}{c}6,96 \\
{[5,95-7,93]}\end{array}$ & $\begin{array}{c}7,51 \\
{[6,12-8,98]}\end{array}$ \\
\hline Гепсидин, пг/мл & $\begin{array}{c}11414,00 \\
{[5040,25-13404,00]}\end{array}$ & $\begin{array}{c}7414,00 \\
{[2929,50-10282,75]^{*}}\end{array}$ \\
\hline Ферритин, нг/мл & $\begin{array}{c}50,90 \\
{[19,58-114,10]}\end{array}$ & $\begin{array}{c}114,80 \\
{[48,90-196,45]^{*}}\end{array}$ \\
\hline Железо, мкмоль/л & $\begin{array}{c}12,00 \\
{[8,00-18,00]}\end{array}$ & $\begin{array}{c}12,00 \\
{[10,25-18,75]}\end{array}$ \\
\hline Трансферрин, мг/дл & $\begin{array}{c}300,00 \\
{[245,00-320,00]}\end{array}$ & $\begin{array}{c}286,00 \\
{[263,50-320,00]}\end{array}$ \\
\hline рТФР, нг/мл & $\begin{array}{c}139,05 \\
{[120,43-161,16]}\end{array}$ & $\begin{array}{c}126,54 \\
{[115,05-141,38]}\end{array}$ \\
\hline Эритроциты, ×10²/л & $\begin{array}{c}4,70 \\
{[4,40-5,08]}\end{array}$ & $\begin{array}{c}4,77 \\
{[4,39-5,16]}\end{array}$ \\
\hline Гемоглобин, г/л & $\begin{array}{c}139,00 \\
{[123,50-151,00]}\end{array}$ & $\begin{array}{c}141,00 \\
{[126,50-151,00]}\end{array}$ \\
\hline Гематокрит, \% & $\begin{array}{c}41,20 \\
{[37,65-43,50]}\end{array}$ & $\begin{array}{c}41,90 \\
{[38,08-44,53]}\end{array}$ \\
\hline Ретикулоциты, \% & $\begin{array}{c}1,53 \\
{[1,25-1,78]}\end{array}$ & $\begin{array}{c}1,76 \\
{[1,46-1,95]}\end{array}$ \\
\hline
\end{tabular}

Примечание. * - достоверность различий по сравнению с аналогичными показателями у пациентов с дислипидемией Ila типа (р<0,05). Данные представлены в виде Ме [Q0,25-Q0,75].

Таблица 10. Состояние параметров воспаления в зависимости от типа диабета и дислипидемии.

\begin{tabular}{lcc}
\hline \multicolumn{1}{c}{ Показатель } & $\begin{array}{c}\text { Сахарный диабет } 1 \text { типа и } \\
\text { Дислипидемия IIb типа }\end{array}$ & $\begin{array}{c}\text { Сахарный диабет 2 типа и } \\
\text { Дислипидемия ІІа типа }\end{array}$ \\
\hline ФНО-а, пг/мл & $14,60[9,78-24,02]$ & $8,61[6,93-13,14]^{*}$ \\
СРБ, нг/мл & $4,00[1,65-19,48]$ & $7,00[5,00-12,00]$ \\
СОЭ, мм/час & $43,00[14,00-56,50]$ & $22,00[5,00-27,25]$ \\
Лейкоциты, ×10/л & $7,02[6,37-10,47]$ & $7,37[6,44-9,60]$ \\
Гепсидин, пг/мл & $9838,00[4216,90-12828,50]$ & $11717,00[8161,75-13404,00]$ \\
Ферритин, нг/мл & $151,20[38,95-270,95]$ & $61,57[31,46-138,85]$ \\
\hline
\end{tabular}

Примечание. * - достоверность различий по сравнению с аналогичными показателями у пациентов с сахарным диабетом 1 типа и дислипидемией Ilb типа $(p<0,05)$. Данные представлены в виде Me [Q0,25-Q0,75]. 
Анемия хронических заболеваний

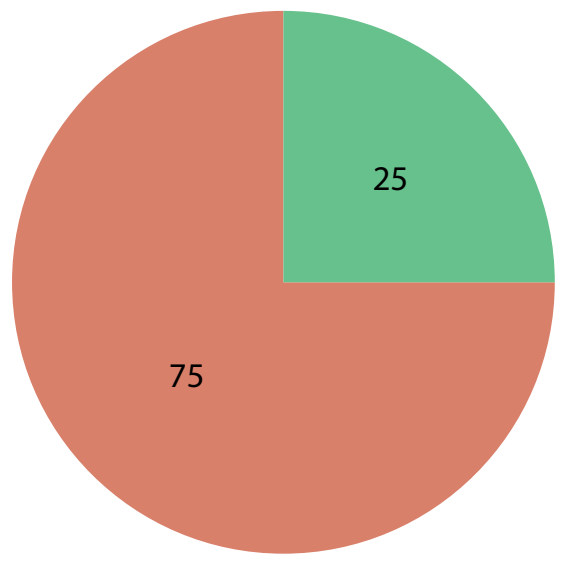

Дислипидемия Ila типа, \%

Дислипидемия IIb типа, \%
Железодефицитная анемия

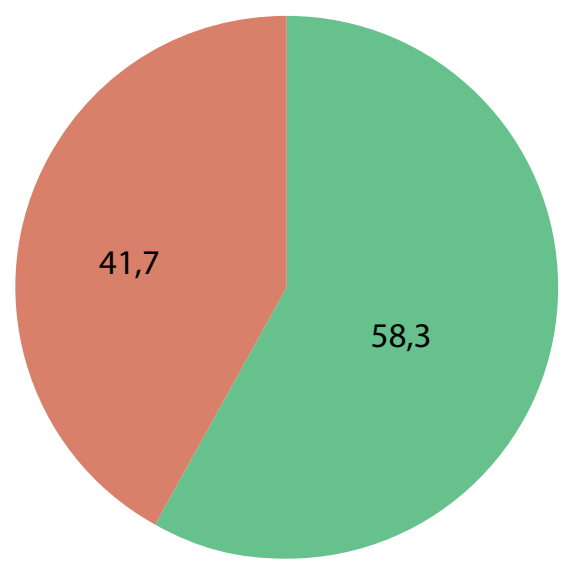

Дислипидемия Ila типа, \%

Дислипидемия Ilb типа, \%

Рисунок 4. Структура дислипидемии у пациентов с сахарным диабетом и анемическим синдромом.

Стоит отметить, что достоверные различия в указанных группах были получены только для концентрации ФНО-а - данный параметр был значимо выше у лиц с сочетанием сахарного диабета 1 типа и дислипидемии Ilb $(p=0,05)$. Данный результат указывает на более значимый вклад типа сахарного диабета (СД1), нежели типа дислипидемии в повышение уровня ФНО-а. Для остальных параметров воспаления уровень статистической значимости различий достигнут не был. Однако обращает внимание явная тенденция к повышению СОЭ и ферритина в подгруппе пациентов с сочетанием сахарного диабета 1 типа и дислипидемии Illb типа, несмотря на то, что данные маркеры были значимо выше у лиц с сахарным диабетом 2 типа вне зависимости от типа дислипидемии.

В общей выборке пациентов с сахарным диабетом и 1, и 2 типа был проведен частотный анализ, который показал, что у пациентов с сахарным диабетом и AX3 преобладал наиболее атерогенный тип дислипидемии (Ilb по D. Fredrickson), тогда как у пациентов с диабетом и ЖДА чаще встречался Ila фенотип $\left(x^{2}=2,743 ; p=0,098\right)$ (рис. 4).

Также была проведена оценка параметров липидного спектра у пациентов с сахарным диабетом 1 и 2 типа в зависимости от наличия и вида анемического синдрома. Результаты представлены в таблице 11.

Как видно из приведенной таблицы, были получены значимые различия содержания общего холестерина, ЛПНП-холестерина и триглицеридов крови в зависимости от вида анемии - у лиц с сахарным диабетом и анемией хронических заболеваний данные показатели были значимо выше, чем у пациентов с сахарным диабетом и сидеропенической анемией. Можно предположить, что данные отличия обусловлены как влиянием субклинического воспаления на развитие $A X 3$, так и его ролью в формировании и прогрессировании дислипидемии, а также потенциальным взаимоотягощающим эффектом нарушений феррокинетики, обмена липидов и воспаления.

Таблица 11. Состояние липидного спектра у пациентов в зависимости от наличия и вида анемии

\begin{tabular}{|c|c|c|c|c|}
\hline & ЖДА & AX3 & $\begin{array}{c}\text { Латентный дефицит } \\
\text { железа }\end{array}$ & Нет анемии \\
\hline $\begin{array}{l}\text { Общий холестерин, } \\
\text { ммоль/л }\end{array}$ & $4,75[4,41-5,28]$ & $5,60[5,10-7,05]^{*}$ & $5,48[4,70-6,48]$ & $5,20[4,33-6,35$ \\
\hline $\begin{array}{l}\text { лПВП-холестерин, } \\
\text { ммоль/л }\end{array}$ & $1,32[0,99-1,79]$ & $1,11[0,85-1,55]$ & $1,25[1,00-1,70]$ & $1,20[1,00-1,50]$ \\
\hline $\begin{array}{l}\text { ЛПнП-холестерин, } \\
\text { ммоль/л }\end{array}$ & $2,60[2,25-3,26]$ & $3,46[3,09-4,42]^{*}$ & $2,95[2,52-3,91]$ & $3,10[2,35-3,94$ \\
\hline $\begin{array}{l}\text { лПОНП-холестерин, } \\
\text { ммоль/л }\end{array}$ & $0,68[0,52-1,05]$ & $0,95[0,53-1,75]$ & $0,59[0,41-1,26]$ & $0,82[0,60-1,18]$ \\
\hline $\begin{array}{l}\text { Триглицериды, } \\
\text { ммоль/л }\end{array}$ & $1,39[0,96-2,28]$ & $2,50[1,45-3,10]^{*}$ & $1,80[0,98-2,55]$ & $1,80[1,14-2,50]$ \\
\hline $\begin{array}{l}\text { Коэффициент } \\
\text { атерогенности }\end{array}$ & $2,92[1,95-4,95]$ & $4,05[2,47-5,23]$ & $3,00[2,36-4,00]$ & $3,40[2,28-4,99]$ \\
\hline
\end{tabular}

Примечание. * - достоверность различий по сравнению с аналогичными показателями у пациентов с ЖДА (р<0,013). Данные представлены в виде $\mathrm{Me}[\mathrm{Q} 0,25-\mathrm{Q} 0,75]$. 
Нежелательные явления

Нежелательных явлений в ходе исследования отмечено не было.

\section{ОБСУЖДЕНИЕ}

\section{Резюме основного результата исследования}

Таким образом, в результате проведенного нами исследования было установлено, что у пациентов с сахарным диабетом как 1, так и 2 типа, имеет место повышение содержания в крови воспалительных маркеров, таких как ФНО-а, СОЭ и СРБ, относительно пациентов с ожирением без НУО и лиц группы здорового контроля. При этом наибольшая концентрация ФНО-а отмечалась у пациентов с сахарным диабетом 1 типа, а повышение концентрации СРБ и СОЭ - у пациентов с сахарным диабетом 2 типа. Также было установлено, что в группе обследованных сахарный диабет 2 типа характеризуется более частым развитием дислипидемии, в структуре которой преобладает более атерогенный тип согласно классификации D. Fredrickson - дислипидемия Ilb, тогда как у пациентов с сахарным диабетом 1 типа чаще встречается Ila дислипидемия. В структуре обследованных нами лиц с сахарным диабетом (вне зависимости от его типа) дислипидемия IIb в сравнении с менее атерогенной IІа дислипидемией характеризовалась более высокими значениями маркеров воспаления - СРБ, СОЭ и ферритина. Анемия хронических заболеваний при сахарном диабете в сравнении с сидеропенической анемией чаще сопровождается дислипидемией IIb и характеризуется более высоким содержанием атерогенных фракций холестерина.

\section{Обсуждение основного результата исследования}

ФНО-а является одним из основных провоспалительных цитокинов и представляет собой пептид с низкой молекулярной массой, который в естественных условиях синтезируется многими типами клеток: мононуклеарными фагоцитами, лимфоцитами, базофилами, эозинофилами, моноцитами, тканевыми макрофагами, нейтрофилами, а также фибробластами и клетками эндотелия сосудов [21]. Известно, что ФНО-а взаимодействует с двумя различными рецепторами - рецептором ФНО 1 (TNFR1) и рецептором ФНО 2 (TNFR2), и реализует провоспалительные эффекты за счёт NF-kB регулируемых белков, таких как IL-6, IL-8, IL-18 и хемокины. Кроме того, через активацию NF- kB ФНО-а способен индуцировать экспрессию самого себя [22]. Еще одним известным источником продукции ФНО-а являются адипоциты, при этом имеются данные о том, что при наличии ожирения способность адипоцитов к синтезу данного цитокина значительно возрастает [23]. Это обуславливает повышение уровня ФНО-а у пациентов с ожирением и синдромом инсулинорезистентности, а также снижение его экспрессии и концентрации в крови при уменьшении массы тела [24]. ФНО-а нарушает чувствительность к инсулину и стимулирует липолиз [25], участвуя в патогенезе сахарного диабета 2 типа.

Имеются данные, подтверждающие важную роль ФНО-а в развитии атеросклероза: как за счет повышения свободных жирных кислот с формированием атерогенного липидного профиля, так и за счет влияния данного цитокина на эндотелий. ФНО-а повышает синтез адгезивных молекул эндотелиальными и гладкомышечными клетками, способствуя проникновению воспалительных клеток в сосудистую стенку, а также - уменьшает образование оксида азота, что угнетает дилатацию сосудов и способствует дисфункции эндотелия [26].

С учетом представленных данных литературы, в нашем исследовании максимальное повышение ФНО-а, как маркера воспаления, ожидалось в группе пациентов с сахарным диабетом 2 типа - данная когорта пациентов характеризовалась достоверно более высоким ИМТ, а также более атерогенным липидным профилем в сравнении с пациентами с сахарным диабетом 1 типа. Однако, согласно результатам исследования, наибольшее повышение сывороточной концентрации ФНО-а имело место именно у пациентов с сахарным диабетом 1 типа. Более того, уровень данного цитокина был значимо выше у лиц с сочетанием сахарного диабета (независимо от типа) и менее атерогенной дислипидемией Ila, чем у пациентов с сахарным диабетом и более атерогенным липидным профилем (Ilb дислипидемия). С учетом проведенного нами субанализа, это связано с тем, что дислипидемия Ila типа значимо чаще встречалась у лиц с сахарным диабетом 1 типа.

В то же время полученные нами результаты в отношении содержания в крови ФНО-а согласуются с некоторыми данными литературы. Так, имеются работы, в которых отмечается повышение концентрации ФНО-а в сыворотке крови больных сахарным диабетом 1 типа, особенно на начальных стадиях заболевания, а также при развитии микроангиопатий $[27,28,29]$. Роль ФНО-а в патогенезе сахарного диабета 1 типа обусловлена способностью данного цитокина стимулировать пролиферацию аутореактивных лимфоцитов, а также вызывать аберрантную экспрессию молекул адгезии и антигенов гистосовместимости II класса на поверхности панкреатических клеток, что приводит к нарушению процессов распознавания антигенов и способствует развитию аутоиммунного инсулита. Кроме того, одним из основных биологических свойств ФНО-а является его участие в рецепторном пути апоптоза иммунокомпетентных клеток [30].

Таким образом, повышение продукции ФНО-а при сахарном диабете, с одной стороны, может быть следствием ожирения, дисгликемии и отражать развитие и прогрессирование микрососудистых осложнений на фоне эндотелиальной дисфункции. С другой стороны - нарушения в системе ФНО-а могут являться первичными, генетически детерминированными и обуславливать, наряду с другими механизмами, иммунопатогенез аутоиммунного сахарного диабета [29].

Стоит отметить и обсудить тот факт, что более низкие значения ФНО-а в группе пациентов с сахарным диабетом 2 типа, согласно результатам нашего исследования, могут быть обусловлены приемом метформина большинством пациентов данной группы. Имеются данные о противовоспалительной активности метформина как in vivo, так и in vitro. Так, в опыте с гепатоцитами животных метформин подавлял ФНО-а индуцированную деградацию негативного регулятора NF- kB lkB, в результате чего имело место ингибирование экспрессии IL-1 $\beta$ и IL-6 [31]. Кроме того, терапия метформином в сочетании с пиоглитазоном в течение 6 месяцев у пациентов с сахарным 
диабетом и ишемической болезнью сердца приводила к статистически значимому снижению уровней ФНО-а и IL-6 [32].

С-реактивный белок является неспецифическим биологическим маркером воспаления, синтезируемым преимущественно печенью и в меньшей степени эндотелиальными клетками [33]. Повышение СРБ у пациентов с сахарным диабетом 2 типа, в нашем исследовании, а также максимальная его продукция у лиц с сочетанием сахарного диабета и дислипидемии IIb типа соотносится с результатами литературы [5, 6, 8, 33]. Известно, что СРБ является независимым предиктором сердечно-сосудистых исходов [34] повышенный уровень данного цитокина ассоциирован не только с риском развития сахарного диабета, артериальной гипертонии и наличием атеросклероза, но и позволяет предсказать развитие основных сердечно-сосудистых событий и смерти, тогда как снижение концентрации СРБ сопровождается уменьшением риска по шкале Framingham. Механизм атерогенного влияния СРБ заключается в подавлении эндотелиального синтеза оксида азота, стимуляции образования сосудосуживающего эндотелина-1 и IL-6, а также повышении экспрессии молекул адгезии и фактора хемотаксиса моноцитов-1 (МСР-1) [35].

Ферритин сыворотки является одним из основных белков, отражающих запас железа в организме. Как правило, гиперферритинемия является отражением нарушений обмена железа, а именно - признаком формирующегося или уже сформированного синдрома перегрузки железом. Однако помимо основной функции регуляции феррокинетики, ферритин играет важную роль в других процессах. Так, концентрация сывороточного ферритина повышается при наличии активного воспалительного процесса в организме, причем здесь его роль изучена недостаточно [36]. Кроме того, было установлено, что сывороточный ферритин имеет довольно высокую чувствительность и специфичность в качестве предиктора сахарного диабета 2 типа у пациентов с хроническим гепатитом (как вирусной, так и неуточненной этиологии), что позволяет использовать его как дополнительный критерий для выявления нарушений углеводного обмена при наличии хронической патологии печени [36]. В нашем исследовании повышение продукции ферритина у пациентов с сахарным диабетом 2 типа относительно лиц группы здорового контроля и пациентов с сахарным диабетом 1 типа наиболее вероятно было обусловлено мезенхимальной реакцией печени воспалительного характера и формированием неалкогольного стеатогепатоза. Об этом же свидетельствует более высокая концентрация ферритина у пациентов с наиболее атерогенной дислипидемией IIb независимо от типа сахарного диабета.

Стоит отметить, что ни в российской, ни в зарубежной литературе не представлено результатов исследования параметров феррокинетики в зависимости от состояния обмена липидов, в том числе у лиц с патологией углеводного обмена. Полученные в ходе нашего исследования результаты свидетельствуют о более атерогенном липидном профиле у лиц с анемией хронических заболеваний в сравнении с железодефицитной анемией и могут отражать влияние хронического низкоинтенсивного воспаления при сахарном диабете как на состояние обмена железа, так и на липидный профиль.
Ограничения исследования

Ограничением данного исследования можно считать относительно небольшой объем групп контроля и сравнения, а также недостаточный объем выборок, сформированных для дополнительного субанализа у пациентов с сахарным диабетом 1 и 2 типа и минорным для данного типа диабета вариантом дислипидемии, в связи с чем достоверные отличия внутри данных выборок были получены только для уровня ФНО-а. Увеличение объема данных выборок может способствовать уточнению влияния характера дислипидемии и типа сахарного диабета на состояние воспалительного статуса пациентов.

\section{ЗАКЛЮЧЕНИЕ}

Таким образом, в результате данного исследования впервые проведен сравнительный анализ фенотипов воспалительного статуса в зависимости от типа сахарного диабета и дислипидемии (согласно классификации D. Fredrickson). Установлено, что сахарный диабет 1 типа ассоциирован с увеличением содержания ФНО-а в крови, а сахарный диабет 2 типа - с повышением концентраций СРБ, ферритина и СОЭ. Дислипидемия IIb типа у пациентов с сахарным диабетом (независимо от его типа) сопровождается повышением значений таких провоспалительных маркеров, как СРБ, ферритин и СОЭ, тогда как дислипидемия Ila характеризуется более высокими значениями ФНО-а и гепсидина.

Иными словами, для лиц с сахарным диабетом 2 типа и более атерогенным профилем дислипидемии (Ilb тип) характерен фенотип локальной воспалительной мезенхимальной реакции печени с повышением острофазных белков, имеющих преимущественно печеночное происхождение (СРБ, ферритин), а для лиц, страдающих сахарным диабетом 1 типа и имеющих менее атерогенный липидный профиль (ІІа тип) - фенотип аутоиммунного, генетически детерминированного воспалительного ответа.

Установлено, что развивающаяся на фоне сахарного диабета анемия хронических заболеваний ассоциирована с более атерогенным липидным профилем, в сравнении с сидеропенической анемией. Оценка состояния обмена железа в зависимости от характера нарушений липидного обмена у пациентов с сахарным диабетом, согласно данным литературы, проведена впервые, и требует дальнейшего изучения на расширенных выборках пациентов.

\section{ДОПОЛНИТЕЛЬНАЯ ИНФОРМАЦИЯ}

Источники финансирования. Исследование выполнено при финансовом обеспечении грантом РФФИ Аспиранты №19-315-90061 «Взаимосвязь нарушений феррокинетики и метаболических изменений при сахарном диабете».

The reported study was funded by RFBR according to the research project №19-315-90061 «Research of carbohydrate metabolism compensation parameters and glycaemia lability in ferrokinetics disorder among patients with diabetes mellitus».

Конфликт интересов. Авторы декларируют отсутствие явных и потенциальных конфликтов интересов, связанных с содержанием настоящей статьи. 
Участие авторов. Мусина Надежда Нурлановна - разработка концепции и дизайна исследования, сбор материала, анализ и интерпретация данных, подготовка текста статьи, внесение правок согласно требованиям рецензентов; Саприна Татьяна Владимировна - разработка концепции и дизайна, написание обоснования рукописи и проверка критически важного интеллектуального содержания, внесение правок согласно требованиям рецензентов, окончательное утверждение рукописи для публикации; Прохоренко Татьяна Сергеевна - сбор материа- ла, анализ и интерпретация данных, написание обоснования рукописи и проверка критически важного интеллектуального содержания; Зима Анастасия Павловна - анализ и интерпретация данных, написание обоснования рукописи и проверка критически важного интеллектуального содержания. Все авторы одобрили финальную версию статьи перед публикацией, выразили согласие нести ответственность за все аспекты работы, подразумевающую надлежащее изучение и решение вопросов, связанных с точностью или добросовестностью любой части работы.

\section{СПИСОК ЛИТЕРАТУРЫ | REFERENCES}

1. Rabinovitch A, Suarez-Pinzon WL. Roles

of cytokines in the pathogenesis and therapy

of type 1 diabetes. Cell Biochem Biophys. 2007:48(2-3):159-163.

doi: https://doi.org/10.1007/s12013-007-0029-2

2. Schneider-Brachert W, Tchikov V, Neumeyer J, et al.

Compartmentalization of TNF Receptor 1 Signaling. Immunity. 2004;21 (3):415-428. doi: https://doi.org/10.1016/j.immuni.2004.08.017

3. Uno S, Imagawa A, Okita K, et al. Macrophages and dendritic cells infiltrating islets with or without beta cells produce tumour necrosis factor-a in patients with recentonset type 1 diabetes. Diabetologia. 2007;50(3):596-601. doi: https://doi.org/10.1007/s00125-006-0569-9

4. Климонтов В.В., Тян Н.В., Фазуллина О.Н., и др. Клинические и метаболические факторы, ассоциированные с хроническим воспалением низкой интенсивности, у больных сахарным диабетом 2 типа // Сахарный диабет. - 2016. -Т. 19. - №4. C. 295-302. [Klimontov W, Tyan NV, Fazullina ON, et al. Clinical and metabolic factors associated with chronic low-grade inflammation in type 2 diabetic patients. Diabetes mellitus. 2016;19(4):295-302. doi: https://doi.org/10.14341/DM7928

5. Wang Z, Shen X-H, Feng W-M, Ye G, Qiu W, Li B. Analysis of Inflammatory Mediators in Prediabetes and Newly Diagnosed Type 2 Diabetes Patients. J Diabetes Res. 2016;2016(4):1-10. doi: https://doi.org/10.1155/2016/7965317

6. Yamamoto Y, Yamamoto H. RAGE-Mediated Inflammation, Type 2 Diabetes, and Diabetic Vascular Complication. Front Endocrinol (Lausanne). 2013;4(4):1-10. doi: https://doi.org/10.3389/fendo.2013.00105

7. Esser N, Legrand-Poels S, Piette J, Scheen AJ, Paquot N. Inflammation as a link between obesity, metabolic syndrome and type 2 diabetes. Diabetes Res Clin Pract. 2014;105(2):141-150. doi: https://doi.org/10.1016/j.diabres.2014.04.006

8. Dandona P, Aljada A, Chaudhuri A, Bandyopadhyay A. The Potential Influence of Inflammation and Insulin Resistance on the Pathogenesis and Treatment of Atherosclerosis-Related Complications in Type 2 Diabetes. J Clin Endocrinol Metab. 2003;88(6):2422-2429. doi: https://doi.org/10.1210/jc.2003-030178

9. Donath MY, Gross DJ, Cerasi E, Kaiser N. Hyperglycemia-induced beta-cell apoptosis in pancreatic islets of Psammomys obesus during development of diabetes. Diabetes. 1999;48(4):738-744. doi: https://doi.org/10.2337/diabetes.48.4.738

10. Klüppelholz B, Thorand B, Koenig W, et al. Association of subclinical inflammation with deterioration of glycaemia before the diagnosis of type 2 diabetes: the KORA S4/F4 study. Diabetologia. 2015;58(10):2269-2277. doi: https://doi.org/10.1007/s00125-015-3679-4

11. Ammirati E, Moroni F, Norata GD, Magnoni M, Camici PG. Markers of Inflammation Associated with Plaque Progression and Instability in Patients with Carotid Atherosclerosis. Mediators Inflamm. 2015;2015(10):1-15. doi: https://doi.org/10.1155/2015/718329

12. Soeki T, Sata M. Inflammatory Biomarkers and Atherosclerosis. Int Heart J. 2016;57(2):134-139. doi: https://doi.org/10.1536/ihj.15-346

13. Hameed I, Masoodi SR, Mir SA, et al. Type 2 diabetes mellitus: From a metabolic disorder to an inflammatory condition. World J Diabetes. 2015;6(4):598. doi: https://doi.org/10.4239/wjd.v6.i4.598

14. Ganz T. Anemia of Inflammation. N Eng/ J Med. 2019;381(12):1148-1157. doi: https://doi.org/10.1056/NEJMra1804281

15. Куфелкина Т.Ю., Валеева Ф.В. Анемия у больных сахарным диабетом 1 типа // Сахарный диабет. - 2010. - №4 - С.49-53. [Kufelkina TY, Valeeva FV. Anemia in patients with type 1 diabetes mellitus. Diabetes mellitus. 2010;13(4):49-53. (In Russ.)] doi: https://doi.org/10.14341/2072-0351-6057
16. Семакова А.Д., Брыкова Я.И., Силина М.Н., Волынкина А.П. Оценка распространенности анемии у больных с сахарным диабетом // Центральный научный вестник. - 2019. - Т. 7. - №72 - С. 7-8. [Semakova AD., Brykova Yl., Silina MN., Volynkina AP. Estimation of the anemia prevalence in patients with diabetes mellitus. Central'nyj naučnyj vestnik. 2019;7(72):7-8. (in Russ.)].

17. Мартынов С.А., Шестакова М.В., Шилов Е.М., Шамхалова М.Ш., и др. Распространенность анемии у больных сахарным диабетом 1 и 2 типа с поражением почек. // Сахарный диабет. - 2017. T.20. - №5 - C.318-328. [Martynov SA, Shestakova M V., Shilov EM, et al. Prevalence of anemia in patients with type 1 and type 2 diabetes mellitus with chronic renal disease. Diabetes mellitus. 2017;20(5):318-328. (In Russ.)] doi: https://doi.org/10.14341/DM9369

18. Румянцев А.Г., Масчан А.А., Чернов В.М., Тарасова И.С. ФГБУ «ФНКЦ ДГОИ имени Дмитрия Рогачева» Минздрава России; Общественная организация Национальное общество детских гематологов, онкологов. Федеральные клинические рекомендации по диагностике и лечению железодефицитной анемии. - 2015. [Rumyantsev AG, Maschan AA, Chernov VM, Tarasova IS; FGBU «FNKC DGOl imeni Dmitriya Rogacheva» Minzdrava Rossii; Obschestvennaia organistsia Natsional'noe obschestvo detskih gematologov, onkologov. Federal'nye klinicheskie rekomendatsii po diagnostike I lecheniiu zhelezodeficitnoi anemii. - 2015. (in Russ.)]

19. Румянцев А.Г., Масчан А.А.; ФГБУ «ФНКЦ ДГОИ имени Дмитрия Рогачева» Минздрава России; Общественная организация Национальное общество детских гематологов, онкологов. Федеральные клинические рекомендации по диагностике и лечению анемии хронических болезней. - 2014. [Rumyantsev AG, Maschan AA, Chernov VM, Tarasova IS; FGBU «FNKC DGOI imeni Dmitriya Rogacheva» Minzdrava Rossii; Obschestvennaia organistsia Natsional'noe obschestvo detskih gematologov, onkologov. Federal'nye klinicheskie rekomendatsii po diagnostike I lecheniiu zhelezodeficitnoi anemii. - 2014. (in Russ.)]

20. Fredrickson DS, Lees RS. Editorial. Circulation. 1965;31(3):321-327. doi: https://doi.org/10.1161/01.CIR.31.3.321

21. Kalliolias GD, Ivashkiv LB. TNF biology, pathogenic mechanisms and emerging therapeutic strategies. Nat Rev Rheumatol. 2016;12(1):49-62. doi: https://doi.org/10.1038/nrrheum.2015.169

22. Aggarwal BB. Signalling pathways of the TNF superfamily: a double-edged sword. Nat Rev Immunol. 2003;3(9):745-756. doi: https://doi.org/10.1038/nri1184

23. Hotamisligil GS. Molecular mechanisms of insulin resistance and the role of the adipocyte. Int J Obes. 2000. doi: https://doi.org/10.1038/sj.ijo.0801497

24. Hauner H, Petruschke T, Russ M, Röhrig K, Eckel J. Effects of tumour necrosis factor alpha (TNFa) on glucose transport and lipid metabolism of newly-differentiated human fat cells in cell culture. Diabetologia. 1995;38(7):764-771. doi: https://doi.org/10.1007/s001250050350

25. Zhang HH, Halbleib M, Ahmad F, et al. Tumor Necrosis FactorStimulates Lipolysis in Differentiated Human Adipocytes Through Activation of Extracellular Signal-Related Kinase and Elevation of Intracellular CAMP. Diabetes. 2002:51(10):2929-2935. doi: https://doi.org/10.2337/diabetes.51.10.2929

26. Gotsman I, Stabholz A, Planer D, et al. Serum cytokine tumor necrosis factor-alpha and interleukin- 6 associated with the severity of coronary artery disease: indicators of an active inflammatory burden? Isr Med Assoc J. 2008;10(7):494-498

27. Ben-Mahmud BM, Chan WH, Abdulahad RM, et al. Clinical validation of a link between TNF-a and the glycosylation enzyme core 2 GlcNAc-T and the relationship of this link to diabetic retinopathy. Diabetologia. 2006;49(9):2185-2191. doi: https://doi.org/10.1007/s00125-006-0332-2 
28. Hussain MJ, Peakman M, Gallati H., et al. Elevated serum levels of macrophage-derived cytokines precede and accompany the onset of IDDM. Diabetologia. 1996;39(1):60-69.

29. Прохоренко Т.С., Саприна Т.В., Лазаренко Ф.Э., и др. Система фактора некроза опухолей а в патогенезе аутоиммунного сахарного диабета // Бюллетень сибирской медицины. - 2011. - Т. 10. - №1. C. 64-69. [Prokhorenko TS, Saprina TV., Lazarenko FE, et al. The system of tumor necrosis factor a in the pathogenesis of autoimmune diabetes mellitus. Bulletin of Siberian Medicine. 2011;10(1):64-69. (in Russ.)] doi: https://doi.org/10.20538/1682-0363-2011-1-64-69

30. Schütze S, Tchikov V, Schneider-Brachert W. Regulation of TNFR1 and CD95 signalling by receptor compartmentalization. Nat Rev Mol Cell Biol. 2008;9(8):655-662. doi: https://doi.org/10.1038/nrm2430

31. Saisho Y. Metformin and Inflammation: Its Potential Beyond Glucose-lowering Effect. Endocrine, Metab Immune Disord Targets. 2015;15(3):196-205 doi: https://doi.org/10.2174/1871530315666150316124019

32. Шаенко 3.А., Расин М.С. Эффективность и безопасность метформина и пиоглитазона у пациентов с ишемической болезнью сердца и сахарным диабетом 2-го типа // Международный эндокринологический журнал. - 2015. - №2. C. 66-70. [Shaenko ZA, Rasin MS. Efficiency and Safety of Metformine and Pioglitazone in Patients with Coronary Heart Disease and
Diabetes Mellitus Type 2. International Journal of Endocrinology 2015;(2):66-70. (In Russ.)]

33. Пизов А.В., Пизов Н.А., Скачкова О.А., Пизова Н.В. Эндотелиальная дисфункция как ранний предиктор атеросклероза // Медицинский алфавит. 2019. - Т.4. - №35. - С.:28-33. [ Pizov A V., Pizov NA, Skachkova OA, Pizova N V. Endothelial dysfunction as early predictor of atherosclerosis. Med Alph. 2020;4(35):28-33. (In Russ.)] doi: https://doi.org/10.33667/2078-5631-2019-4-35(410)-28-33

34. Koenig W, Löwel H, Baumert J, Meisinger C. C-Reactive Protein Modulates Risk Prediction Based on the Framingham Score. Circulation. 2004;109(11):1349-1353. doi: https://doi.org/10.1161/01.CIR.0000120707.98922.E3

35. Соловьева А.Е., Кобалава ЖД. Перспективы противовоспалительной терапии атеросклероза // Клиническая фармакология и терапия. 2014. - T.23. - №3. - C.28-38. [Solovyeva AE, Kobalava ZhD. Perspective of antiinflammatory treatment for atherosclerosis. Kliničeskâa farmakologiâ iterapiâ. 2014,23(3):28-38. (In Russ.)].

36. Пальцев И.В., Калинин АЛ., Сницаренко Е.Н. Сывороточный ферритин-предиктор сахарного диабета 2 типа у пациентов с хроническими гепатитами // Проблемы здоровья и экологии. 2016. - T. 2. - №48. - C. 65-68. [Paltsev IV, Kalinin AL, Snitsarenko EN. Serum ferritin as a predictor of diabetes mellitus type 2 in patients with chronic hepatitis. Problemy zdorov'â i èkologii. 2016;2(48):65-68. (In Russ.)].

\section{ИНФОРМАЦИЯ ОБ АВТОРАХ [AUTHORS INFO]:}

* Мусина Надежда Нурлановна, аспирант [Nadezhda N. Musina, MD, postgraduate student]; адрес: 634050, Томск, Московский тракт, д. 2 [address: 2, Moscowski Trakt, Tomsk, 634050 Russia]; ORCID: http://orcid.org/0000-0001-7148-6739; eLibrary SPIN: 3468-8160; e-mail: nadiezhda-musina@mail.ru

Саприна Татьяна Владимировна, д.м.н., профессор [Tatiana V. Saprina, MD, PhD, Professor]; ORCID: http://orcid.org/0000-0001-9011-8720; eLibrary SPIN: 2841-2371; e-mail: tanja.v.saprina@mail.ru Зима Анастасия Павловна, д.М.н., профессор [Anastasia P. Zima, MD, PhD, Professor]; ORCID: http://orcid.org/0000-0002-9034-7264; eLibrary SPIN: 5710-4547; e-mail: zima2302@gmail.com Прохоренко Татьяна Сергеевна, к.M.н. [Tatiana S. Prokhorenko, MD, PhD]; ORCID: http://orcid.org/0000-0002-8016-4755; eLibrary SPIN: 1495-4127; e-mail: mmikld.ssmu@gmail.com

*Автор, ответственный за переписку / Corresponding author.

\section{ЦИТИРОВАТЬ:}

Мусина Н.Н., Саприна Т.В., Прохоренко Т.С., Зима А.П. Особенности параметров обмена железа и воспалительного статуса у пациентов с сахарным диабетом и дислипидемией // Ожирение и метаболизм. - 2020. - Т. 17. - №3. C. 269-282. doi: https://doi.org/10.14341/omet12497

\section{TO CITE THIS ARTICLE:}

Musina NN, Saprina TV, Prokhorenko TS, Zima AP. Iron metabolism parameters and inflammatory status in patients with diabetes mellitus and dyslipidemia. Obesity and metabolism. 2020;17(3):269-282. doi: https://doi.org/10.14341/omet12497 